\title{
Pastas de ultra-alto desempenho submetidas a cura sob pressão
}

\author{
Ultra-high performance pastes under pressure curing
}

\section{Carolina Noda Livi Wellington Longuini Repette}

\section{Resumo}

A

aplicação de pressão em misturas cimentícias tem efeitos positivos no desenvolvimento da microestrutura e nas propriedades mecânicas da matriz endurecida. Contudo, os benefícios têm sido estudados em níveis altos de pressão ou combinados com cura térmica. Este artigo está inserido em uma pesquisa em que foi proposto um equipamento alternativo para propiciar tanto a cura sob pressão quanto térmica em condições de fácil reprodução. Foram reportados os resultados obtidos considerando o efeito da pressão aplicada nas primeiras horas de hidratação, com cargas de 0,1 MPa, $5 \mathrm{MPa}$ e $10 \mathrm{MPa}$. Através dos ensaios de massa específica, módulo de elasticidade dinâmico e resistência à compressão, verificou-se a relação positiva entre aumento de pressão e desempenho mecânico. Foram conduzidos ensaios de microscopia eletrônica de varredura, porosimetria e termogravimetria, nos quais se verificou a influência da pressurização no desenvolvimento de uma matriz compacta e homogênea, porém com aumento da microporosidade e diminuição da quantidade de produtos de hidratação formados. Os resultados indicam que um desempenho mecânico satisfatório não depende exclusivamente do grau de hidratação do cimento, mas da sinergia entre produtos formados e alterações na estrutura de poros.

Palavras-chave: Pressurização. Estado fresco. Mistura cimentícias. Microestrutura. Propriedades mecânicas.

\begin{abstract}
Compaction pressure has positive effects on the development of the microstructure and mechanical properties of hardened cementitious mixtures. However, the benefits have been studied at high-pressure levels or combined with thermal curing. This article is part of a research project that proposed an alternative equipment to promote both pressure and thermal curing, in conditions that are easy to reproduce. The paper reports the results obtained from the study of the isolated effect of the pressure applied in the first hours of hydration, with loads of 0,1 MPa, $5 \mathrm{MPa}$ and $10 \mathrm{MPa}$. The relationship between pressure increments and mechanical performance was checked by means of density, modulus of dynamic elasticity and compressive strength tests. Scanning electron microscopy, porosimetry and thermogravimetry analyses were carried out. They showed the influence of pressurizing on the development of a compact and homogeneous matrix, but with an increase in microporosity and a decrease in the amount of hydration products formed. The results indicate that a satisfactory mechanical performance does not depend exclusively on the degree of hydration of the cement, but on the synergy between hydration products and changes in the pore structure.
\end{abstract}

Keywords: Pressurizing. Fresh state. Cementitious mixtures. Microstructure. Mechanical properties. 


\section{Introdução}

O concreto de ultra-alto desempenho (CUAD), como o nome sugere, é um concreto com uma ou mais propriedades superiores, seja de resistência, durabilidade ou estabilidade no longo prazo. Os primeiros estudos datam da década de 1970, quando pesquisadores investigavam formas de diminuir a porosidade para melhorar a resistência à compressão através da combinação entre cura térmica e sob pressão (ROY; GOUDA; BOBROWSKY, 1972; BAJZA, 1983).

Posteriormente, com o advento dos concretos de pós reativos (CPR), concluiu-se que o desempenho diferenciado do CUAD atual é possível melhorando-se a homogeneidade e a compacidade da matriz. A homogeneidade decorre da limitação do tamanho máximo das partículas, uma vez que não é incorporado o agregado graúdo, enquanto a compacidade é aprimorada por uma otimização granulométrica dos materiais e pela aplicação de pressão antes ou durante o endurecimento (RICHARD; CHEYREZY, 1995).

O efeito positivo da aplicação gradativa de pressão nas primeiras horas permite eliminar o excesso de água e o ar incorporado, diminuir a porosidade (ROY; GOUDA; BOBROWSKY, 1972; NEMATZADEH; NAGHIPOUR, 2012) e reduzir a relação entre custo e resistência (İPEK et al., 2011).

Trabalhos pioneiros estudaram o efeito de pressurizar as pastas com cargas de $345 \mathrm{MPa}$ até $689 \mathrm{MPa}$ durante $5 \mathrm{~h}$ em temperatura ambiente (ROY; GOUDA; BOBROWSKY, 1972); de 204 MPa durante 3 min (BAJZA, 1983); e de $50 \mathrm{MPa}$ durante 30 min (RICHARD; CHEYREZY, 1995).

Por outro lado, o efeito de uma pressurização mais baixa (6,8 MPa), com hidrocâmara e pistão flutuante, foi estudado por Zhou e Beaudoin (2003) em pastas de cimento endurecidas. Entre $8 \mathrm{~h}$ e $10 \mathrm{~h}$, a água atingiu facilmente os grãos de cimento anidro, e a pressão pouco influenciou o grau de hidratação. Em um estágio intermediário (entre 15 h e 18 h), a migração da água ocorreu em menor taxa devido ao enrijecimento da matriz, contudo a aplicação de pressão induziu microfissuras, que permitiram a movimentação da água. No estágio final (20 h), a pasta apresentou resistência suficiente para resistir à abertura de microfissuras e o grau de hidratação foi pouco influenciado pela pressão externa.

Estudos em corpos de prova de concreto de ultraalto desempenho foram conduzidos com prensas de laboratório com até $125 \mathrm{MPa}$ de pressurização durante 6 dias (İPEK et al., 2011; İPEK; YILMAZ; UYSAL, 2012) e com até $82 \mathrm{MPa}$ durante $3 \mathrm{~min}$ (ŽIVICA; KRIŽMA, 2011). Dispositivos com macaco hidráulico foram desenvolvidos e monitoravam uma pressão axial de até $50 \mathrm{MPa}$ durante 24 h (JUSTS et al., 2013) ou lateral na parede do molde $(18,9 \mathrm{MPa})$ durante $30 \mathrm{~min}$ (NEMATZADEH; NAGHIPOUR, 2012).

Além destes, um equipamento foi apresentado para testar o efeito de altas pressões confinantes. Com uma prensa hidráulica de $5.000 \mathrm{kN}$, moldes cilíndricos de $70 \mathrm{~mm}$ de diâmetro interno, $150 \mathrm{~mm}$ de diâmetro externo e $180 \mathrm{~mm}$ de altura, pressões de até $1.200 \mathrm{MPa}$ foram aplicadas, e os autores estudaram o efeito de diferentes concentrações de areia em argamassas com relação a/c fixa em 0,50 (YANKELEVSKY et al., 2018).

Pressões mais baixas são utilizadas em câmaras de vácuo. A combinação entre 0 aquecimento fornecido por dispositivo de micro-ondas com uma câmara de vácuo acoplada aplicado após a desforma (1 dia após a mistura) apresentou resultados interessantes em termos de manutenção da temperatura, da umidade e da resistência dos corpos de prova. A pressão utilizada foi de $30 \mathrm{kPa}$ e $50 \mathrm{kPa}$ em pastas de cimento com relação a/c fixa de 0,38 , 0,45 e 0,75 , e a temperatura no corpo de prova superou $70^{\circ} \mathrm{C}$, dependendo da posição do magneto utilizado para gerar a micro-onda. A respeito apenas do efeito do vácuo, os autores concluíram que as pressões utilizadas não interferiram na umidade do corpo de prova e que as diferenças de resultados de resistência à compressão devem-se ao fator a/c utilizado (MAKUL; VONGPRACUBCHAI; RATTANADECHO, 2018).

Em âmbito nacional, o efeito da pressão geralmente está combinado com temperatura, sendo investigado no contexto de pastas para cimentação de poços de petróleo em células de pressão (ROCHA, 2015) ou de concretos curados em autoclave (ANDRADE, 2015). Rocha (2015) verificou que o aumento da pressão de cura até 89 $\mathrm{MPa}$, na temperatura de $60{ }^{\circ} \mathrm{C}$, acelerou as reações de hidratação acompanhadas por velocidade de propagação de pulso ultrassônico, porém sem efeitos significativos na resistência à compressão. Já a cura em autoclave com pressão de 0,15 MPa com temperatura de $150{ }^{\circ} \mathrm{C}$, iniciada no estado fresco ou endurecido, mostrou-se negativa em relação a uma cura úmida convencional.

Um estudo mais recente a respeito da cura em autoclave em CUAD, em níveis de pressão de 0,5 MPa, $1 \mathrm{MPa}$ e 1,5 MPa, aplicados durante $6 \mathrm{~h}$ a 12 $\mathrm{h}$ após a desforma dos corpos de prova, e temperatura de $156{ }^{\circ} \mathrm{C}, 183{ }^{\circ} \mathrm{C}$ e $203{ }^{\circ} \mathrm{C}$ respectivamente, mostrou que existem pontos ótimos de pressão e duração da cura que foram de 
1,0 MPa e $10 \mathrm{~h}$ respectivamente. Contudo, os autores mencionam que o nível ideal de pressão é dependente da quantidade de cinza volante utilizada na composição dos concretos (CHEN; GAO; REN, 2018).

Percebe-se grande variação nos parâmetros da cura em condição de pressão, seja quanto aos níveis de carga, duração do processo e forma de aplicação da pressão. De Larrard e Sedran (1994) afirmam que a alta pressão demanda um procedimento técnico que, por vezes, é de difícil aplicação em elementos estruturais em escala real, porém continua sendo uma alternativa para obter CUAD.

Além disso, uma vez que existem restrições e dificuldades tecnológicas na aplicação de pressões superiores a $10 \mathrm{MPa}$ (JUSTS et al., 2013), torna-se interessante adotar valores inferiores.

Sendo assim, com o propósito de contribuir com o conhecimento a respeito da hidratação de matrizes cimentícias compactadas no estado fresco, este trabalho avalia o efeito de diferentes níveis de pressão aplicada com um equipamento simples e robusto. Destaca-se que a pressão foi aplicada de forma monoaxial, através de um mecanismo de transmissão de carga com pistões, que permitiu a compactação simultânea de quatro corpos de prova ainda no estado fresco. Além do mecanismo de compactação, os moldes foram projetados de modo a permitir a expulsão homogênea do excesso de água com o andamento da pressurização.

\section{Materiais e métodos}

\section{Materiais e preparação das pastas}

$\mathrm{O}$ estudo foi realizado em pasta de cimento CP VARI e sílica ativa (SA). A composição de óxidos determinada por fluorescência de raios $\mathrm{X}$ e a massa específica por picnometria de hélio encontram-se na Tabela 1. Adicionalmente, foi calculada a composição potencial de Bogue para o cimento, considerando as devidas correções necessárias devido à presença de fíler, segundo metodologia apresentada em Betioli (2007).

\section{Preparação das pastas}

A partir de testes preliminares com o ensaio de miniabatimento e critérios de misturas cimentícias de ultra-alto desempenho, foi determinado o traço em massa de 1:0,25:0,25:1,1\% (cimento : sílica ativa : água/cimento : aditivo). $\mathrm{O}$ aditivo foi um superplastificante do tipo policarboxilato com teor de sólidos de 47,1\%, determinado segundo a NBR 10908:1990 (ABNT, 1990) e foi dosado em relação à massa de cimento Portland. A quantidade de água presente no aditivo foi descontada da água de amassamento.

Tabela 1 - Características físicas e químicas dos materiais

\begin{tabular}{l|c|c}
\hline \multicolumn{1}{c}{ ÓXIDOS (\%) } & CP V & SA \\
\hline $\mathrm{SiO}_{2}$ & 19,0 & 84,9 \\
$\mathrm{Al}_{2} \mathrm{O}_{3}$ & 2,5 & $<0,04$ \\
$\mathrm{Fe}_{2} \mathrm{O}_{3}$ & 2,8 & 2,2 \\
$\mathrm{CaO}$ & 63,3 & 1,2 \\
$\mathrm{MgO}$ & 4,2 & 2,0 \\
$\mathrm{SO}_{3}$ & 3,1 & 0,8 \\
$\mathrm{~K}_{2} \mathrm{O}$ & - & 2,5 \\
$\mathrm{Na}_{2} \mathrm{O}$ & - & 1,2 \\
$\mathrm{TiO}_{2}$ & - & 0,4 \\
$\mathrm{Mn}_{2} \mathrm{O}$ & - & 2,0 \\
$\mathrm{P}_{2} \mathrm{O}_{5}$ & - & $<0,01$ \\
\hline \multicolumn{3}{|c}{ FÍSICAS } \\
\hline $\mathrm{Perda}_{2}$ ao fogo & 4,4 & 4,0 \\
$\mathrm{Massa}$ específica (g/cm $\left.{ }^{3}\right)$ & 3,07 & 2,26 \\
\hline \multicolumn{2}{c}{ BOGUE* } & \multicolumn{2}{c}{ CP V } \\
\hline $\mathrm{C}_{3} \mathrm{~S}$ & \multicolumn{2}{c}{52,24} \\
$\mathrm{C}_{2} \mathrm{~S}$ & 15,07 \\
$\mathrm{C}_{3} \mathrm{~A}$ & 1,89 \\
$\mathrm{C}_{4} \mathrm{AF}$ & \multicolumn{3}{c}{8,52} \\
\hline
\end{tabular}

Nota: Legenda:

*cálculo potencial de Bogue;

CP V: Cimento Portland CP V - ARI; e

SA: Sílica ativa. 
Após a pesagem, os materiais secos foram homogeneizados manualmente e gradualmente incorporados à água com aditivo previamente dissolvido. A mistura ocorreu em um agitador mecânico Tedemix com frequência de agitação de $25 \mathrm{~Hz}$ (equivalente a $733 \mathrm{RPM}$ ), durante 4 min e 30 s. Depois de 2 min foi realizada uma pausa para remover o material aderido às paredes da cuba.

\section{Cura dos corpos de prova}

Para este trabalho foram utilizados moldes cilíndricos e metálicos, apresentados na Figura 1, com diâmetro interno de 20 mm e altura de 105 mm. A altura extra foi prevista para compensar perdas de volume provocadas pela pressurização.
O equipamento é ilustrado na Figura 2. A pressão foi aplicada através de um sistema mecânico contendo a combinação de braço de alavanca e polias, de tal forma que a vantagem mecânica foi de 2,25. Assim, a colocação de uma massa de $71,2 \mathrm{~kg}$ na extremidade do braço de alavanca resultou em uma pressão aplicada de $10 \mathrm{MPa}$.

Para garantir a distribuição uniforme da carga no mesmo eixo, considerando a trajetória em arco do braço de alavanca, foram colocadas uma placa superior e uma inferior, além de uma base móvel, que se movimenta de modo a corrigir possíveis excentricidades. O movimento é guiado por dois eixos e rolamentos lineares.

\section{Figura 1 - Moldes cilíndricos, pistão e base desenvolvidos para este trabalho}

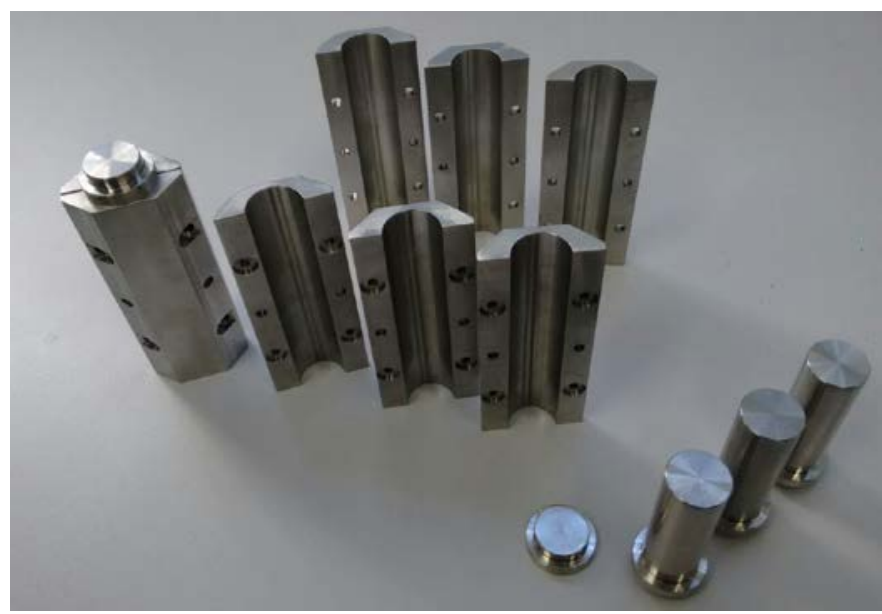

\section{Figura 2 - Equipamento desenvolvido}

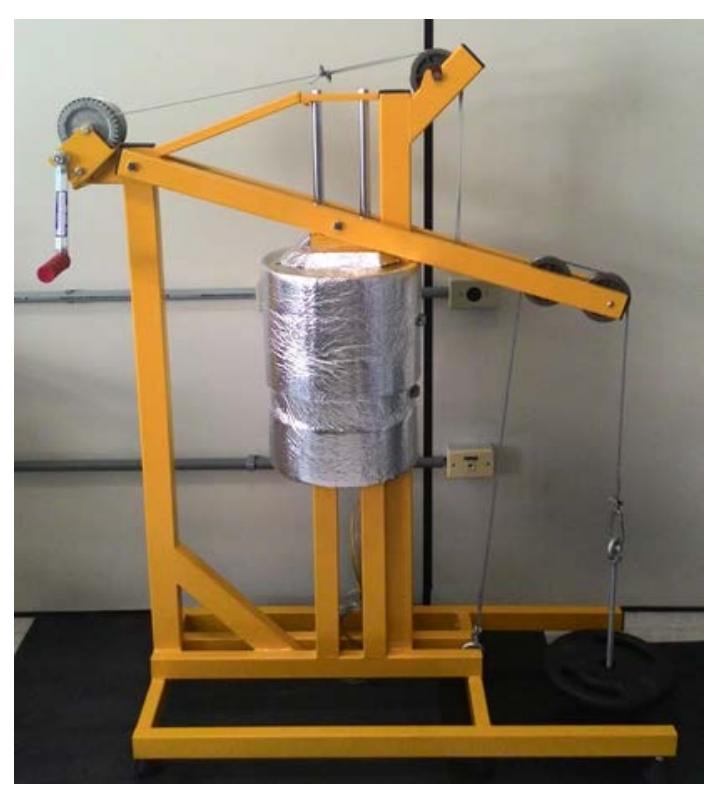

(a) Sistema completo

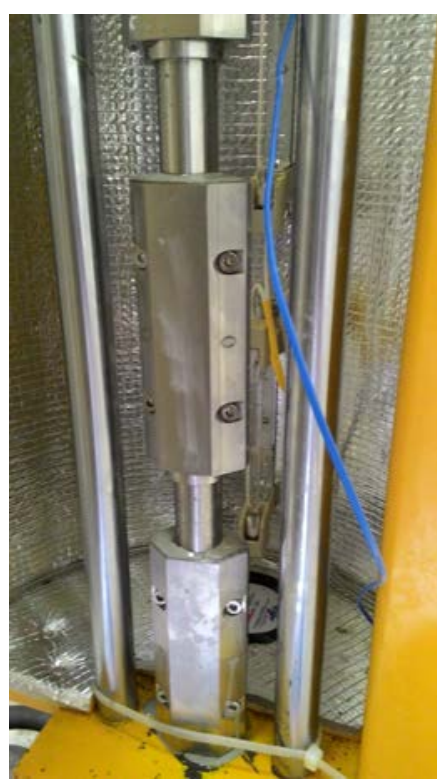

(b) Colocação dos corpos de prova em série, com detalhe para o pistão 
Os moldes foram preenchidos com pasta, em camada única, e compactados com haste metálica. Na sequência, foram posicionados em série. Entre cada molde foi colocado um pistão, responsável pela transferência uniforme de pressão durante todo o processo, além de uma trava para garantir o início de pressurização igual para todos os corpos de prova.

A aplicação de carga iniciou-se 30 min após o contato da água com o cimento. Esse foi o tempo necessário para proceder com a mistura dos materiais e o posicionamento dos moldes no equipamento. A trava foi retirada e foram aplicadas pressões de compactação de $5 \mathrm{MPa}$ e $10 \mathrm{MPa}$, em temperatura ambiente e umidade controlada. Após 22 h e 30 min dessa cura sob pressão, os corpos de prova foram retirados dos moldes, identificados e submetidos às leituras de massa, volume e módulo de elasticidade. Por fim, foram acondicionados em tanque com água saturada com cal, em câmara úmida.

Para controle, foram preparados corpos de prova não compactados, mantidos em pressão atmosférica, no mesmo laboratório, com as mesmas condições de temperatura e umidade. A fim de evitar a evaporação da água, a superfície foi protegida com material plástico.

\section{Propriedades física e mecânicas}

Foram testados 4 corpos de prova para cada condição de cura, sendo determinadas as propriedades de módulo de elasticidade dinâmico e resistência à compressão, sobre as quais se descreve adiante. Adicionalmente, foi estimada a massa específica, conforme recomenda a ASTM C39/C39M (AMERICAN..., 2016).

\section{Massa específica}

A massa específica foi estimada a partir da razão entre massa e volume, a fim de monitorar a eficiência da compactação. Foram realizadas três medições de diâmetro e altura, para cálculo do volume; e uma de massa (AMERICAN..., 2016), nas idades de 1 dia (após o desmolde), 7 dias e 28 dias (em condição saturada, logo após a remoção do tanque de cura).

\section{Módulo de elasticidade dinâmico}

Realizou-se o ensaio de módulo de elasticidade dinâmico nas idades de 1,7 e 28 dias em equipamento Sonelastic (ATCP Engenharia), no Laboratório de Aplicações de Nanotecnologia em Construção Civil da Universidade Federal de Santa Catarina (Nanotec-Lab/ECV/UFSC). Foram impostos três impactos ao longo da extensão do corpo de prova, sendo registrado o menor valor medido, conforme descreve a ASTM C215 (AMERICAN..., 2014).

É sabido que os trabalhos experimentais na área de materiais cimentícios determinam o módulo de elasticidade estático. Entretanto, trabalhos conduzidos no grupo Nanotec-Lab (AZEVEDO, 2015), na Escola de Engenharia de São Carlos da USP (PRADO; HAACH, 2013), entre outras instituições (CASTRO; MARTINS, 2016), estão apresentando resultados coerentes; e com boa correlação com a resistência à compressão de elementos de concreto (JULIANI, 2014). Além de ser rápido e com baixa variabilidade, é um ensaio não destrutivo, o que permite o monitoramento do mesmo corpo de prova ao longo do tempo (SARTORI, 2015).

\section{Resistência à compressão}

Para o ensaio de resistência à compressão aos 7 e 28 dias, os corpos de prova foram ajustados em cortadeira metalográfica Isomet (Buehler) com o objetivo de manter a relação altura : diâmetro igual a 2, bem como garantir o paralelismo das faces (ASSOCIAÇÃO..., 2007; AMERICAN..., 2016).

O ensaio foi realizado em prensa universal Shimadzu, do Laboratório de Materiais de Construção Civil da UFSC (LMCC/ECV/UFSC), com capacidade de $20.000 \mathrm{kN}$, a uma taxa de aplicação de carga de $0,5 \mathrm{MPa} / \mathrm{s}$. Uma rótula de 30 mm de diâmetro foi colocada sobre o corpo de prova.

\section{Caracterização microestrutural}

A caracterização microestrutural foi realizada em fragmentos coletados após a ruptura à compressão. A hidratação foi interrompida com nitrogênio líquido, e a água retirada por sublimação em um liofilizador Enterprise (Terrone). As amostras foram mantidas em dessecador. Optou-se pela liofilização, em vez de secagem a $105{ }^{\circ} \mathrm{C}$, para evitar que a água do C-S-H e da etringita fosse eliminada nesta etapa, o que poderia comprometer, principalmente, os resultados de termogravimetria (SCRIVENER et al., 2015).

Além da termogravimetria, as amostras foram avaliadas quanto à porosidade e à morfologia da superfície fraturada.

\section{Termogravimetria}

O ensaio de termogravimetria foi realizado em um Analisador Térmico Simultâneo TA Instruments, Modelo SDT-Q600, do Nanotec-Lab. O equipamento conta com uma faixa de medição de 
temperatura ambiente de até $1.500 \quad{ }^{\circ} \mathrm{C} \quad$ e sensibilidade de massa de $0,1 \mu \mathrm{g}$.

Aproximadamente $20 \mathrm{mg}$ de amostra moída foi depositada em cadinho de alumínio sem tampa. A amostra foi aquecida a uma taxa de $20{ }^{\circ} \mathrm{C} / \mathrm{min}$ da temperatura ambiente até $1.000^{\circ} \mathrm{C}$. Para a purga dos gases e proteção da termobalança foi utilizado gás nitrogênio líquido 5.0 analítico.

Os valores de massa foram corrigidos em função da massa residual (TAYLOR, 1997; MADANI; BAGHERI; PARHIZKAR, 2012).

Com isso, foram avaliados o grau de hidratação e a concentração de portlandita nas idades de 7 e 28 dias. O grau de hidratação, a partir da quantidade de água não evaporável, foi calculado com a Equação 1 (MADANI; BAGHERI; PARHIZKAR, 2012), sendo para a quantidade de água não evaporável, considerando a hidratação completa, adotado o valor de 0,23 (MADANI; BAGHERI; PARHIZKAR, 2012; MEHTA; MONTEIRO, 2014; NEVILLE, 2016).

$\alpha_{n}(t)=\frac{m_{n}(t)}{m_{c} \cdot m_{n \infty}}$

Onde:

$\alpha_{n}(t)$ : grau de hidratação a partir da água não evaporável;

$m_{n}(t)$ : quantidade de água não evaporável no instante $t$, dada pela perda de massa de até $500{ }^{\circ} \mathrm{C}$;

$m_{c}$ : razão em massa do cimento em relação aos materiais cimentícios; e

$m_{n \infty}$ : quantidade de água não evaporável para a hidratação completa do cimento.

O teor de portlandita foi utilizado como indicador da reação pozolânica. Foi calculado a partir da perda de massa na faixa de temperatura entre 400 ${ }^{\circ} \mathrm{C}$ e $500{ }^{\circ} \mathrm{C}$, considerando a estequiometria e o balanço de massas envolvidos na desidratação dela, conforme a Equação 2 (SCRIVENER et al., 2015).

$\mathrm{Ca}(\mathrm{OH})_{2} \rightarrow \mathrm{CaO}+\mathrm{H}_{2} \mathrm{O}$

Eq. 2

Onde:

$\% \mathrm{CaOH}(t)$ : teor de hidróxido de cálcio no instante $\mathrm{t}(\%)$; e

$\Delta m_{400-500}$ : perda de massa de água referente à decomposição do hidróxido de cálcio, na faixa de $400{ }^{\circ} \mathrm{C}$ a $500{ }^{\circ} \mathrm{C}(\%)$.

Contudo, durante o processo de manipulação e preparo das amostras, uma parcela de $\mathrm{CaO}$ pode reagir e formar $\mathrm{CaCO}_{3}$, de modo que o teor de portlandita foi corrigido pela Equação 3 e Equação 4 (KRAKOWIAK et al., 2015). Além dessa correção, também foi descontada a concentração de fases carbonáticas provenientes do cimento
Portland utilizado que poderiam estar relacionadas à decomposição do carbonato de cálcio.

$$
\begin{aligned}
& \mathrm{CaO}+\mathrm{CO}_{2} \rightarrow \mathrm{CaCO}_{3} \\
& \% \mathrm{CaOH}(t)^{\prime}=\% \mathrm{Ca}(\mathrm{OH})_{2}+1,68 . \Delta m_{500-800}
\end{aligned}
$$

Onde:

$\% \mathrm{CaOH}(t)^{\prime}$ : teor de hidróxido de cálcio corrigido (\%); е

$\Delta m_{500-800}$ : perda de massa referente à decomposição do anidro carbônico, na faixa de $500{ }^{\circ} \mathrm{C}$ a $800{ }^{\circ} \mathrm{C}$.

\section{Porosidade}

Para análise de porosidade, foram realizadas medidas de porosimetria por intrusão de mercúrio, utilizando-se o Porosímetro Micromeritics Autopore IV, do Laboratório de Física Nuclear Aplicada da Universidade Estadual de Londrina (UEL).

Cerca de 2 g de amostra foram colocados no penetrômetro e submetidos a vácuo. Na sequência o mercúrio foi injetado, e o sistema foi colocado em baixa pressão $(3,5 \mathrm{kPa})$ e, depois, em alta pressão (até 227,5 MPa), o que permitiu a leitura de poros na faixa de 0,005 $\mu \mathrm{m}$ até $353 \mu \mathrm{m}$. O tempo de equilíbrio em cada patamar, para leitura de volume e pressão, foi de 5 min.

Considerando os poros cilíndricos, a pressão aplicada e as características físicas do mercúrio, calculou-se o diâmetro equivalente através da Equação de Washburn (Equação 5).

$d=-\frac{4 \cdot \gamma \cdot \cos (\theta)}{p}$

Eq. 5

Onde:

$d$ : diâmetro equivalente do poro $(\mu \mathrm{m})$;

$\gamma$ : tensão superficial do mercúrio $(0,485 \mathrm{~N} / \mathrm{m})$;

$\theta$ : ângulo de contato entre o mercúrio e o sólido $\left(130^{\circ}\right)$; e

$p$ : pressão aplicada $(\mathrm{Pa})$.

Para cada nível de pressão, registrou-se o volume de mercúrio intrudido por grama de amostra (ml/g). Os dados de volume foram normalizados em relação à massa da amostra, e a porosidade foi calculada a partir da Equação 6.

$P=\frac{V_{n}}{V_{a b s, a}} .100$

Eq. 6

Onde:

$P$ : porosidade (\%, $\mathrm{ml} / \mathrm{ml})$;

$V_{n}$ : volume normalizado em relação à massa da amostra (ml); e 
$V_{a b s, a}$ : volume absoluto da amostra, calculado a partir da densidade absoluta da amostra (ml).

\section{Morfologia da superfície fraturada}

As imagens foram obtidas em um microscópio eletrônico de varredura Hitachi TM3030, do Laboratório Cermat - Núcleo de Pesquisa em Materiais Cerâmicos e Compósitos, do Departamento de Engenharia Mecânica da UFSC (Cermat/EMC/UFSC). Foi utilizada uma tensão de aceleração de $15 \mathrm{kV}$. Os fragmentos foram fixados no suporte com uma fita adesiva de carbono, sendo em seguida recobertos com uma camada de ouro.

\section{Resultados e discussão}

\section{Propriedades física e mecânicas}

As propriedades avaliadas foram a massa específica, o módulo de elasticidade dinâmico e a resistência à compressão. Os gráficos apresentam o valor médio dos resultados obtidos, e a barra de erros corresponde a mais ou menos um desvio padrão (para cima e para baixo). Foram realizadas análises de variância e testes de grupos homogêneos pelo método de Tukey, para um nível de confiança de $95 \%$.

\section{Massa específica}

Os valores médios de massa específica, obtidos nas idades de 1, 7 e 28 dias, foram plotados na Figura 3. A análise de variância pode ser conferida na Tabela 2.

Essa propriedade manteve-se constante ao longo do tempo (1, 7, 28 dias), variando apenas com a pressão aplicada, e apresentou valores médios de $2,21 \mathrm{~g} / \mathrm{cm}^{3}$ (pressão atmosférica), 2,35 g/ $\mathrm{cm}^{3}$ (5 $\mathrm{MPa})$ e $2,40 \mathrm{~g} / \mathrm{cm}^{3}$ (10 MPa). Dada a simplicidade de sua determinação, pode ser entendida como parâmetro de controle para avaliação da eficiência da compactação das pastas no estado fresco, fato este também observado por İpek et al. (2011).

Figura 3 - Efeito da pressão na massa específica com 1, 7 e 28 dias

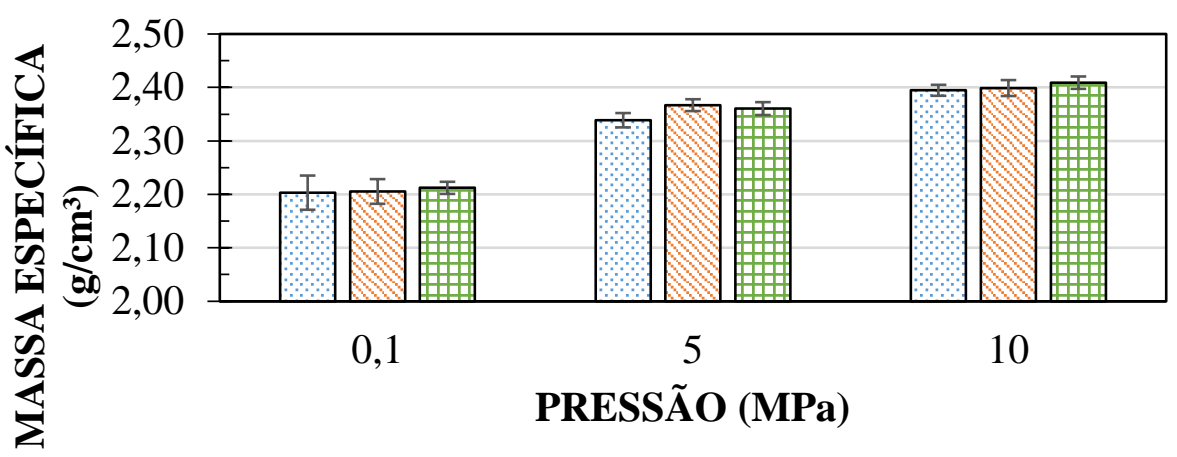

$\square 1$ dia $\quad 07$ dias $\square 28$ dias

Tabela 2 - Análise de variância para a massa específica

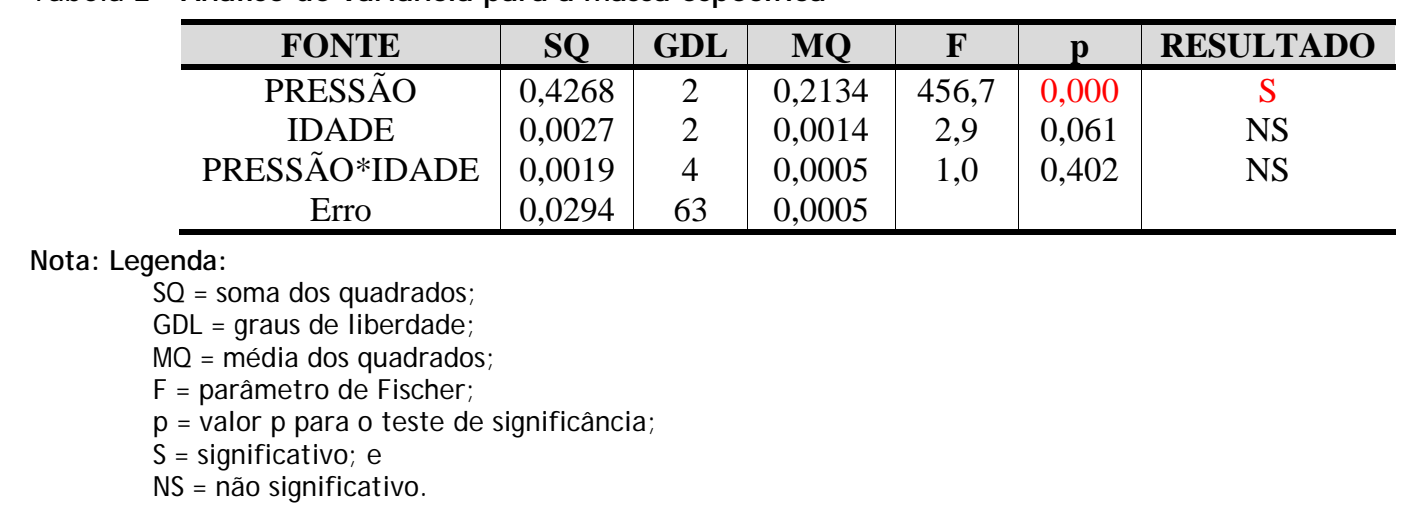

Sabendo-se que o excesso de água foi expulso com a compactação e a partir dos valores de massa específica, estimou-se a quantidade real de água presente na mistura após a compactação. Considerando que o volume de ar presente é constante para todas as misturas, o volume da pasta 
foi igual ao somatório dos volumes de cimento, sílica ativa, água e aditivo. Sendo assim, as pastas não compactadas apresentaram volume igual a 0,68 $\mathrm{cm}^{3}$, que corresponde a uma massa de 1,496 g. A massa também permaneceu aproximadamente constante em todos os corpos de prova, de modo que a quantidade de água nas pastas reduziu de 0,25 (pressão atmosférica) para 0,20 (pressão de $5 \mathrm{MPa}$ ) e 0,19 (pressão de $10 \mathrm{MPa}$ ).

Conforme se comprova nos dados seguintes, o aumento da densidade da matriz (RICHARD; CHEYREZY, 1995; ZHOU; BEAUDOIN, 2003) tem reflexos positivos na resistência à compressão (IIPEK; YILMAZ; UYSAL, 2012) e no módulo de elasticidade (NEMATZADEH; NAGHIPOUR, 2012).

\section{Módulo de elasticidade}

O módulo de elasticidade dinâmico foi sensível aos efeitos da idade e do nível de pressão aplicada. Na Figura 4 observou-se a evolução progressiva dessa propriedade ao longo do tempo, indicando o desenvolvimento da microestrutura.

Assim como a massa específica, o módulo foi favorecido continuamente com o aumento da pressão de compactação. Logo após o desmolde, foram obtidos valores médios de $27 \mathrm{GPa}, 35 \mathrm{GPa}$ e 38 GPa para cada nível de pressão, representando ganhos de $21 \%$ e $32 \%$ para $5 \mathrm{MPa}$ e $10 \mathrm{MPa}$ em relação a 0,1 $\mathrm{MPa}$. Aos 28 dias foram obtidos valores médios de $35 \mathrm{GPa}, 41 \mathrm{GPa}$ e $44 \mathrm{GPa}$ para 0,1 $\mathrm{MPa}, 5 \mathrm{MPa}$ e $10 \mathrm{MPa}$ de pressão respectivamente. Comparando as pastas compactadas das mantidas em pressão atmosférica, os ganhos foram de $18 \%$ e $27 \%$. As diferenças significativas foram confirmadas pela análise de variância (Tabela 3).

\section{Figura 4 - Efeito da pressão e idade no módulo de elasticidade dinâmico}

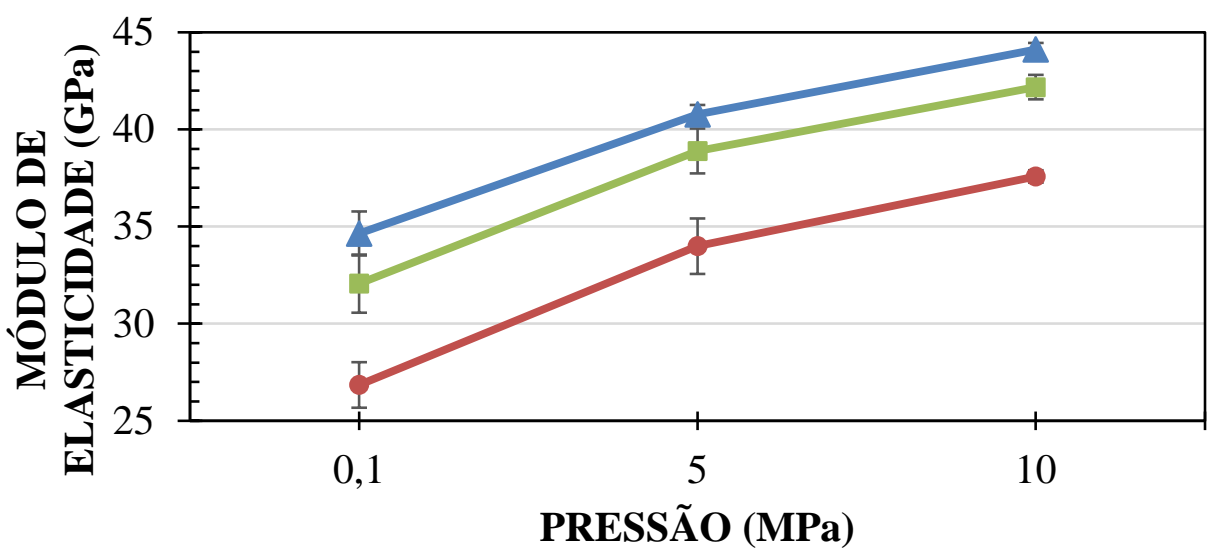

$\rightarrow 1$ dia $\rightarrow-7$ dias $\leftarrow-28$ dias

Tabela 3 - Análise de variância para o módulo de elasticidade

\begin{tabular}{c|c|c|c|c|c|c}
\hline FONTE & SQ & GDL & MQ & F & p & RESULTADO \\
\hline PRESSÃO & $1.395,06$ & 2 & 697,53 & 553,370 & 0,000 & S \\
IDADE & 410,49 & 2 & 205,25 & 162,830 & 0,000 & S \\
PRESSÃO*IDADE & 10,44 & 4 & 2,61 & 2,070 & 0,094 & NS \\
Erro & 84,45 & 67 & 1,26 & & & \\
\hline
\end{tabular}

Nota: Legenda:

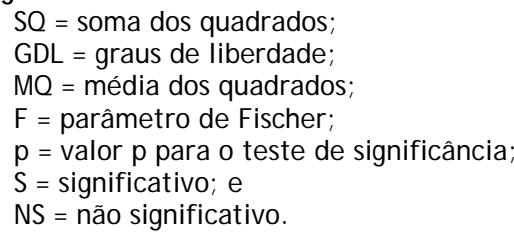


Outra constatação interessante é que os corpos de prova compactados com apenas $5 \mathrm{MPa}$ apresentaram um módulo de elasticidade logo após o desmolde similar àquele dos corpos de prova não compactados e com 28 dias. Esse resultado tem um impacto tecnológico positivo, pois, com base no critério de rigidez de uma peça de concreto, podese liberar precocemente o elemento e, com isso, antecipar o reúso de formas.

Sabe-se que o módulo de elasticidade varia com a presença de agregados e com o método de determinação, entre outros fatores. Contudo, não foram encontrados registros de dados experimentais para módulo de elasticidade dinâmico em pastas. Sendo assim, pode-se apenas fazer uma comparação superficial com Nematzadeh e Naghipour (2012), em que foi avaliado o efeito da pressurização de concretos convencionais, com uma resistência à compressão alvo de $30 \mathrm{MPa}$, com diferentes relações água-cimento. No caso das amostras compactadas, o módulo de elasticidade estático aos
28 dias apresentou pouca variação, diferentemente do observado em amostras não compactadas. Outra conclusão relevante foi o aumento da propriedade com o processo de pressurização, que, para uma relação água-cimento de 0,55 , foi de $25 \mathrm{GPa}$ para $38 \mathrm{GPa}$. O incremento, superior a 50\%, confirmou uma relação positiva entre pressão e melhoria na propriedade (NEMATZADEH; NAGHIPOUR, 2012).

\section{Resistência à compressão}

Os resultados de resistência à compressão para 7 e 28 dias, considerando os três níveis de pressão, foram plotados na Figura 5. Ficou evidente o efeito favorável da pressão e da idade (Tabela 4), sendo o ganho expressivo de resistência aos 28 dias observado para os corpos de prova compactados com $10 \mathrm{MPa}$, que apresentaram resultados 29\% superiores aos não compactados (166 MPa e 129 MPa respectivamente).

\section{Figura 5 - Influência da pressão e idade nos valores de resistência à compressão}

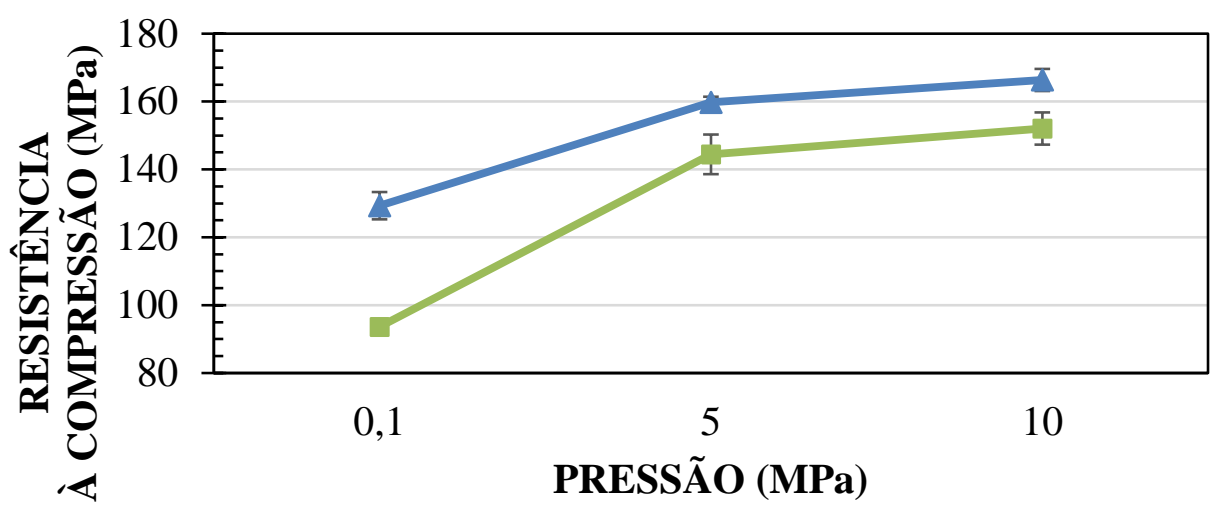

-7 dias -28 dias

Tabela 4 - Análise de variância para resistência à compressão

\begin{tabular}{c|c|c|c|c|c|c}
\hline FONTE & SQ & GDL & MQ & F & p & RESULTADO \\
\hline PRESSÃO & $14.154,5$ & 2 & $7.077,3$ & 386,150 & 0,000 & S \\
IDADE & $3.255,1$ & 1 & $3.255,1$ & 177,600 & 0,000 & S \\
PRESSÃO*IDADE & 780,5 & 2 & 390,2 & 21,290 & 0,000 & S \\
Erro & 421,5 & 23 & 18,3 & & & \\
\hline
\end{tabular}

Nota: Legenda:

$\mathrm{SQ}=$ soma dos quadrados;

$\mathrm{GDL}=$ graus de liberdade;

$\mathrm{MQ}=$ média dos quadrados

$\mathrm{F}=$ parâmetro de Fischer;

$\mathrm{p}=$ valor $\mathrm{p}$ para 0 teste de significância;

$\mathrm{S}=$ significativo; e

NS = não significativo. 
Diferentemente dos parâmetros anteriores, a resistência à compressão foi influenciada tanto pela pressão, quanto pela idade e interação entre os fatores. É importante destacar que o desenvolvimento de resistência com a pressão não segue um crescimento linear, de modo que com 5 MPa o incremento de resistência aos 28 dias, em relação à amostra não compactada, foi de $23 \%$. Além disso, o aumento da pressão é mais significativo nas primeiras idades, o que comprova o efeito acelerador decorrente da diminuição da água disponível para hidratação, maior aproximação das partículas e consequente diminuição dos espaços disponíveis para crescimento dos produtos hidratados (AÏTCIN, 2000).

Embora tenha sido comprovada a eficiência da compactação das pastas no estado fresco, no contexto de aplicação da técnica deve-se avaliar a necessidade do uso de pressões elevadas. Os resultados obtidos sugerem ser satisfatória a aplicação de $5 \mathrm{MPa}$. Conclusão similar foi observada por İpek et al. (2011) e por Justs et al. (2013) para os níveis de pressão de 25 MPa e 10 MPa respectivamente.

Tal desenvolvimento reflete a diminuição da relação água-cimento, obedecendo à Lei de Abrams, como mostra a Figura 6, em que os resultados de resistência à compressão foram plotados em relação à quantidade de água real presente após a compactação das misturas.

Sendo assim, os resultados obtidos comprovam a eficiência da compactação das pastas de cimento no estado fresco, e em um contexto de aplicação prática da técnica torna-se relevante avaliar a necessidade do uso de pressões elevadas, de modo que parece satisfatório limitar-se à aplicação de 5 MPa. Essa conclusão também foi observada em İpek et al. (2011) e Justs et al. (2013).
Em İpek et al. (2011) combinou-se a compactação no estado fresco com cura térmica no estado endurecido com vapor a $90{ }^{\circ} \mathrm{C}$ durante 3 dias, seguida de $12 \mathrm{~h}$ a $300{ }^{\circ} \mathrm{C}$ em ar seco. Os resultados de resistência à compressão aumentaram progressivamente até uma pressão de $125 \mathrm{MPa}$, com valores de $206 \mathrm{MPa}$ (não compactado), 420 $\mathrm{MPa}$ (compactado com $25 \mathrm{MPa}$ ) e $475 \mathrm{MPa}$ (compactado com $100 \mathrm{MPa}$ ). Como principal conclusão tem-se que, embora a máxima resistência tenha sido alcançada com elevada pressão, o ganho de resistência é significativo para a menor pressão empregada (25 MPa).

Já Justs et al. (2013) utilizaram apenas a compactação no estado fresco, em temperatura ambiente, e obtiveram resultados de resistência aos 28 dias de $104 \mathrm{MPa}, 137 \mathrm{MPa}, 140 \mathrm{MPa}, 143 \mathrm{MPa}$, $147 \mathrm{MPa}$ e $154 \mathrm{MPa}$ para amostras não compactadas e com pressão de $10 \mathrm{MPa}, 20 \mathrm{MPa}, 30$ $\mathrm{MPa}, 40 \mathrm{MPa}$ e $50 \mathrm{MPa}$ respectivamente. Para os autores, o resultado obtido para $10 \mathrm{MPa}$ torna essa pressão satisfatória, sem necessidade do uso de valores mais elevados.

Para um mesmo nível de pressão, o desenvolvimento de resistência de 7 para 28 dias é positivo e constatado igualmente em Helmi et al. (2016). Em cada idade, na amostra referência, os resultados foram de $78 \mathrm{MPa}$ e $90 \mathrm{MPa}$, enquanto, quando compactadas, foi de $85 \mathrm{MPa}$ e $119 \mathrm{MPa}$. Segundo os autores, com aplicação de pressão reduzem-se a presença e o diâmetro dos macrodefeitos. Proporcionalmente, a amostra compactada apresenta maior volume de poros total a ser preenchido pelos produtos de hidratação. Menciona-se que a relação água-cimento foi de 0,40, que a pressão foi aplicada após o endurecimento e que não há detalhes quanto ao tipo de carregamento adotado ou mecanismos para retirada do excesso de água e ar.

Figura 6 - Resistência à compressão em função da relação a/c real

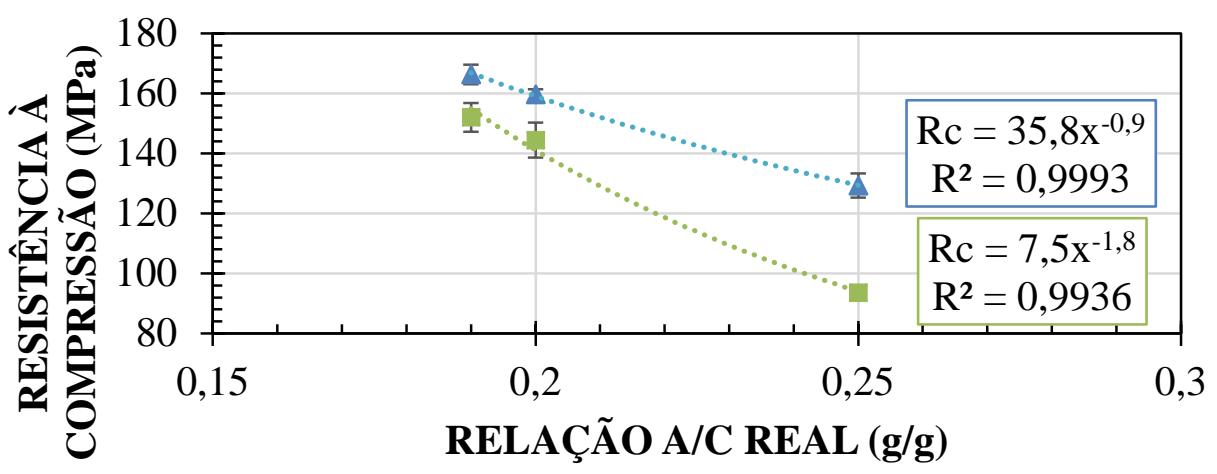

$\square$ dias $\Delta 28$ dias 


\section{Caracterização microestrutural}

\section{Morfologia da superfície fraturada}

A aplicação de pressão modifica o tamanho dos poros, o que pode alterar a morfologia dos produtos hidratados. Nesse sentido, as matrizes foram estudadas em imagens de microscopia eletrônica de varredura (MEV), com ampliações de 150x e 200x, em amostras com 28 dias de hidratação submetidas a cura em pressão atmosférica (Figura 7a), com 5 MPa (Figura 7b) e 10 MPa (Figura 7c).

As matrizes mostraram-se homogêneas. No caso da amostra compactada com $10 \mathrm{MPa}$ (Figura 7c), observou-se a presença de material granular na superfície, mas sem alterações morfológicas significativas.

Figura 7 - Microfotografias obtidas através de microscopia eletrônica de varredura - elétrons secundários da superfície fraturada das amostras com barra de escala e ampliação (a) P0,1 - $500 \mu \mathrm{m}$,

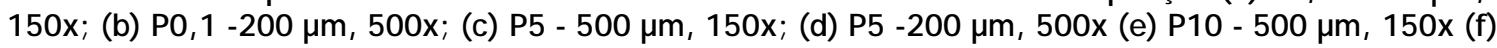
P10 - $200 \mu \mathrm{m}$, 500x

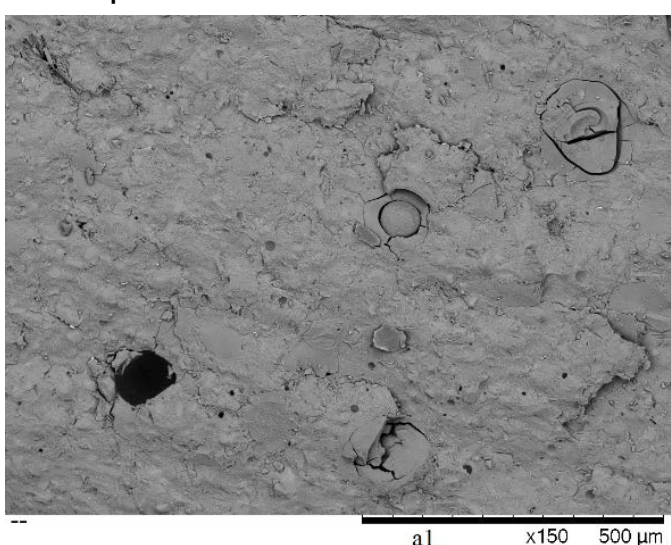

(a)

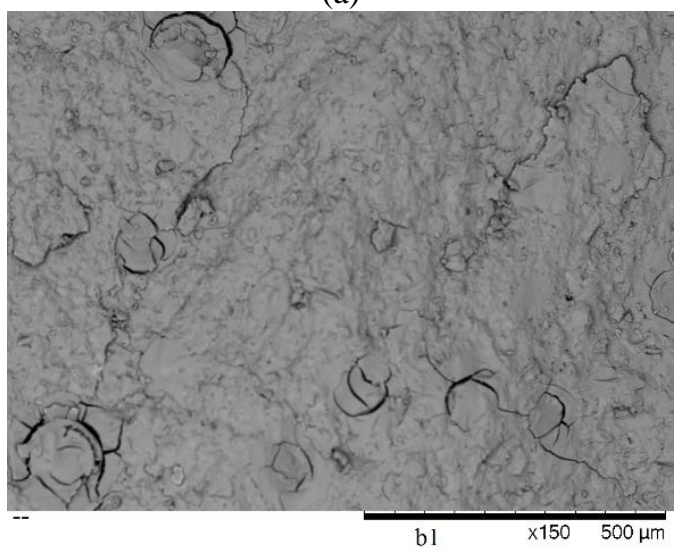

(c)

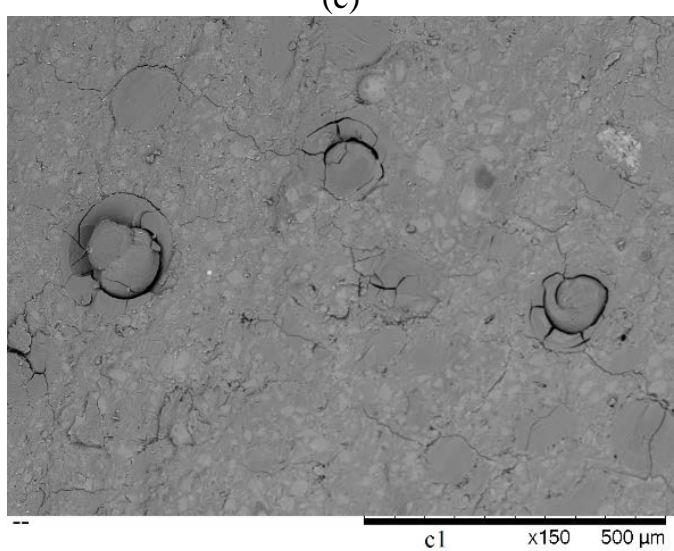

(e)

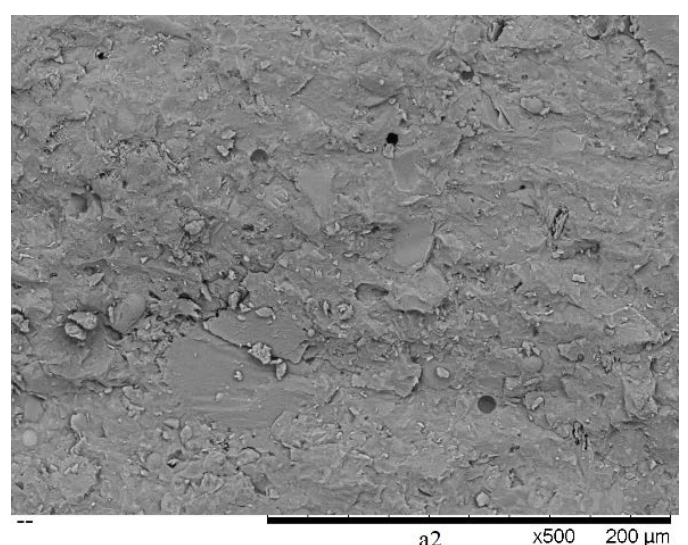

(b)

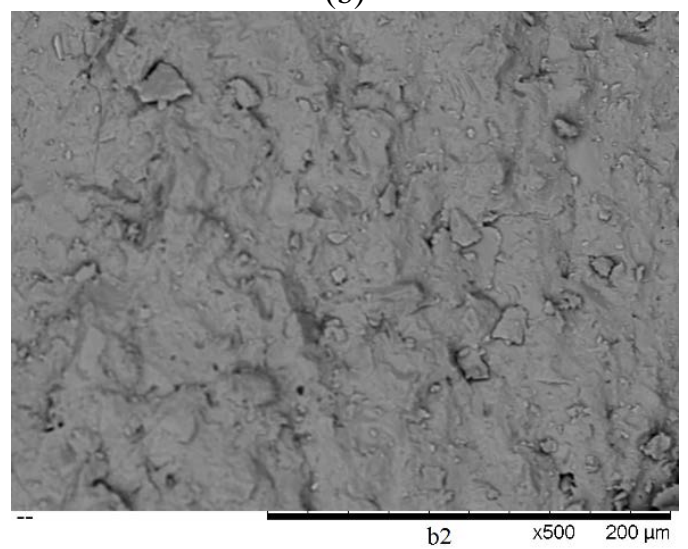

(d)

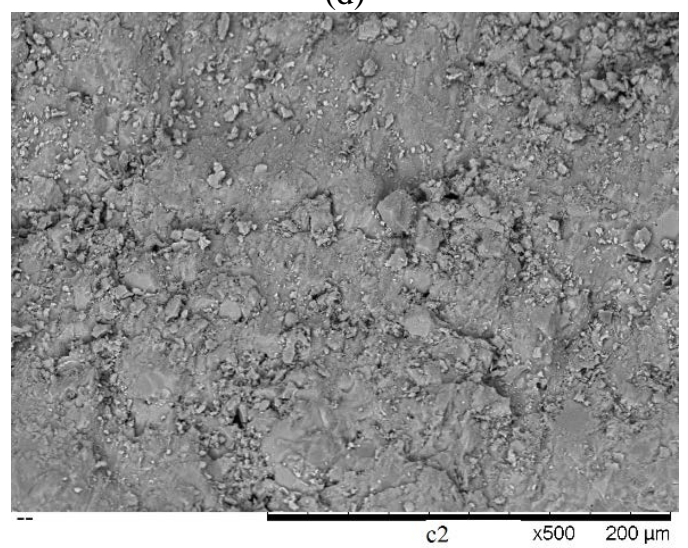

(f) 
Com o aumento da pressão de compactação, tornouse cada vez menos porosa. Na amostra P0,1 foram identificadas bolhas de ar da ordem de $100 \mu \mathrm{m}$ e vazios capilares de $31 \mu \mathrm{m}$ a 7,8 $\mu \mathrm{m}$. Na amostra P5 os vazios capilares foram inferiores a 7,8 $\mu \mathrm{m}$. Não foram detectados poros dessa grandeza na amostra P10. Além da compacidade, foram observados aglomerados de sílica não reagida, cuja concentração aumentou com o nível de pressão aplicado.

\section{Porosidade}

A intepretação dos poros por MEV foi coerente com os dados de porosimetria, cujas curvas de porosidade e incremento foram plotadas na Figura 8.

Foi possível detectar poros na faixa de $353 \mu \mathrm{m}$ a $0,005 \mu \mathrm{m}$. Os valores de porosidade total foram de $6,1 \%, 10,3 \%$ e $9,7 \%$ para as amostras preparadas com 0,1 MPa, 5 MPa e $10 \mathrm{MPa}$ de compactação respectivamente.

Embora a amostra submetida à cura ambiente em pressão atmosférica tenha resultado em menor porosidade total (6\%), as amostras compactadas sofreram maior refinamento dos poros. Observouse redução progressiva da concentração das bolhas de ar, de $2,4 \%$ para $1,0 \%$ e $0,6 \%$, com o aumento da pressão de compactação. Os macroporos, ou capilares maiores, sofreram pouca alteração, variando entre 2,7\%, 3,0\% e 3,8\%. O efeito da pressão de compactação foi expressivo na concentração de microporos, ou capilares menores, que aumentou de 1,1\% para 6,4\% e 5,3\%. Em função do limite de injeção de mercúrio, não foi possível quantificar os poros de gel (inferiores a 0,002 $\mu \mathrm{m})$.

A distribuição dos poros é usualmente um indicador do grau de hidratação, uma vez que, com o avanço da formação dos produtos hidratados, os poros capilares tendem a diminuir, mas os poros de gel aumentam (NEVILLE, 2016; TAYLOR, 1997). Porém, obteve-se aumento da concentração dos poros capilares devido aos microporos. Em um estudo com amostras submetidas à pressão de 8 $\mathrm{MPa}$, os autores associaram esse resultado à possível expansão dos produtos hidratados, já que a compactação reduz a fissuração por retração e o volume de grandes defeitos (HELMI et al., 2016).

\section{Figura 8 - Curvas de porosidade das amostras com 28 dias}
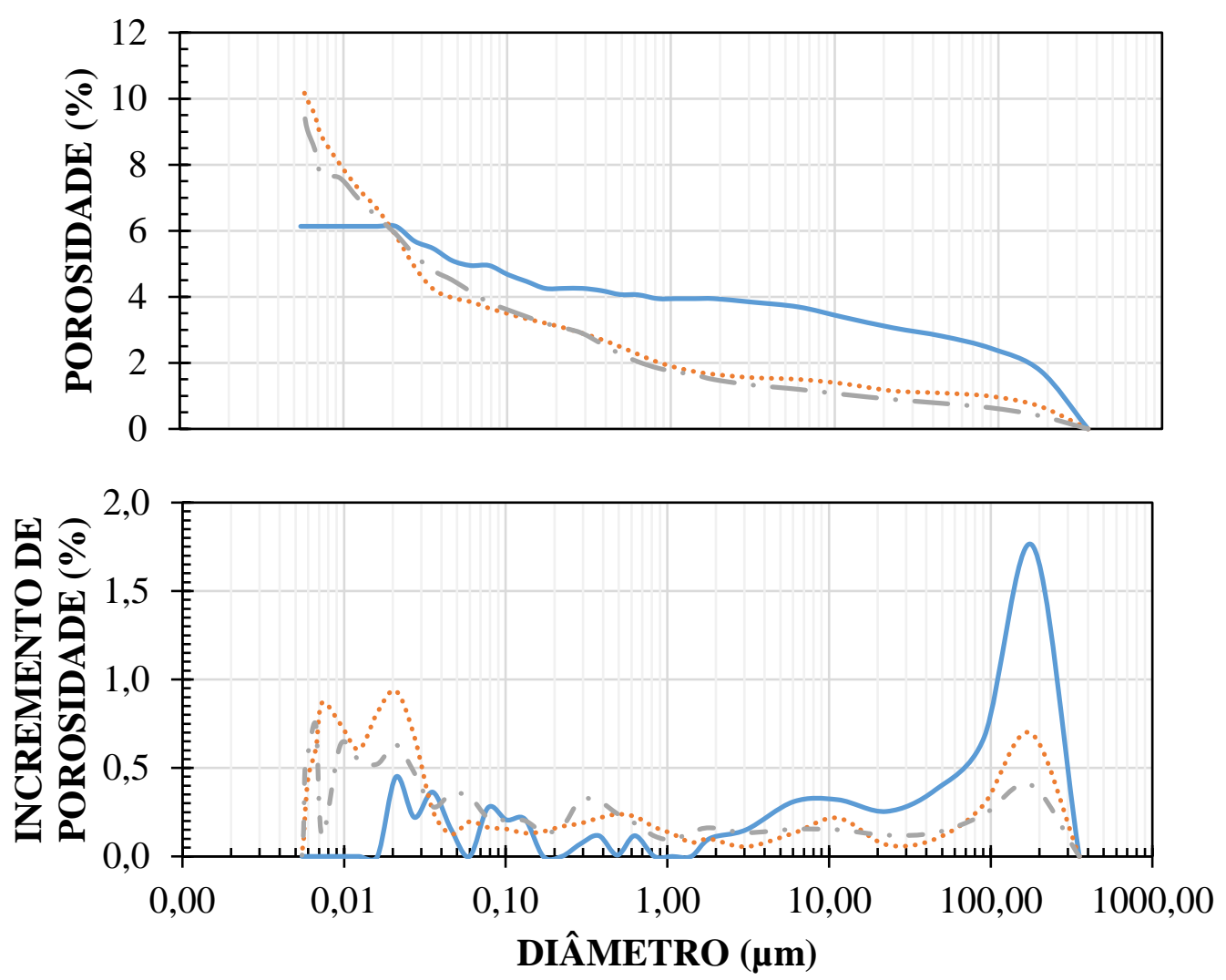

$\longrightarrow$ 0,1 MPa $\cdots \cdots . . .0,5 \mathrm{MPa} \quad-.10 \mathrm{MPa}$ 
Também é relatado que em sistemas pozolânicos a estrutura de poros apresenta maior concentração dos pequenos poros de gel devido à reação da portlandita com as pequenas partículas de sílica, formando um C-S-H que ocupa o espaço anteriormente preenchido por ambos (KRAKOWIAK et al., 2015).

Além disso, já foi exposto que a movimentação da água promove alterações na microestrutura da pasta. A água mobiliza-se por vazios cada vez menores, criando conexões entre poros de gel e capilares, até um nível crítico em que a passagem fica restrita aos poros de gel (HELMI et al., 2016).

\section{Análise termogravimétrica}

A análise termogravimétrica foi realizada nas amostras com 7 e 28 dias, e as curvas foram plotadas na Figura 9. A aplicação de pressão não alterou o perfil das curvas, de modo que foram observados os três picos de perda de massa, associados a (1) desidratação dos hidratos de silicatos e aluminatos, (2) desidratação do hidróxido de cálcio e (3) decomposição das fases carbonáticas.

Uma vez identificados os picos, foram quantificadas as concentrações de massa de água não evaporável (ANE), utilizada para a estimativa do grau de hidratação (GDH), bem como a concentração de portlandita experimental $(\mathrm{CH})$, conforme a Figura 10.

Registrou-se diminuição do teor de água não evaporável e de portlandita com o aumento da pressão de compactação. Justifica-se isso pelo fato de que, quanto maior a pressão, maior a retirada de água disponível para reação e diminuição dos espaços disponíveis para o crescimento ordenado dos cristais de portlandita.

Comparando resultados de 28 dias em relação a 7 dias, tem-se uma evolução no grau de hidratação medido, com valores de 7,8\% para amostra não compactada, $15,5 \%$ para $5 \mathrm{MPa}$ e 6,2\% para 10 MPa. No caso da portlandita, registrou-se aumento de $7,8 \%$ e de $2,1 \%$, e redução de $6,2 \%$ respectivamente.

Figura 9 - Curvas de termogravimetria das amostras
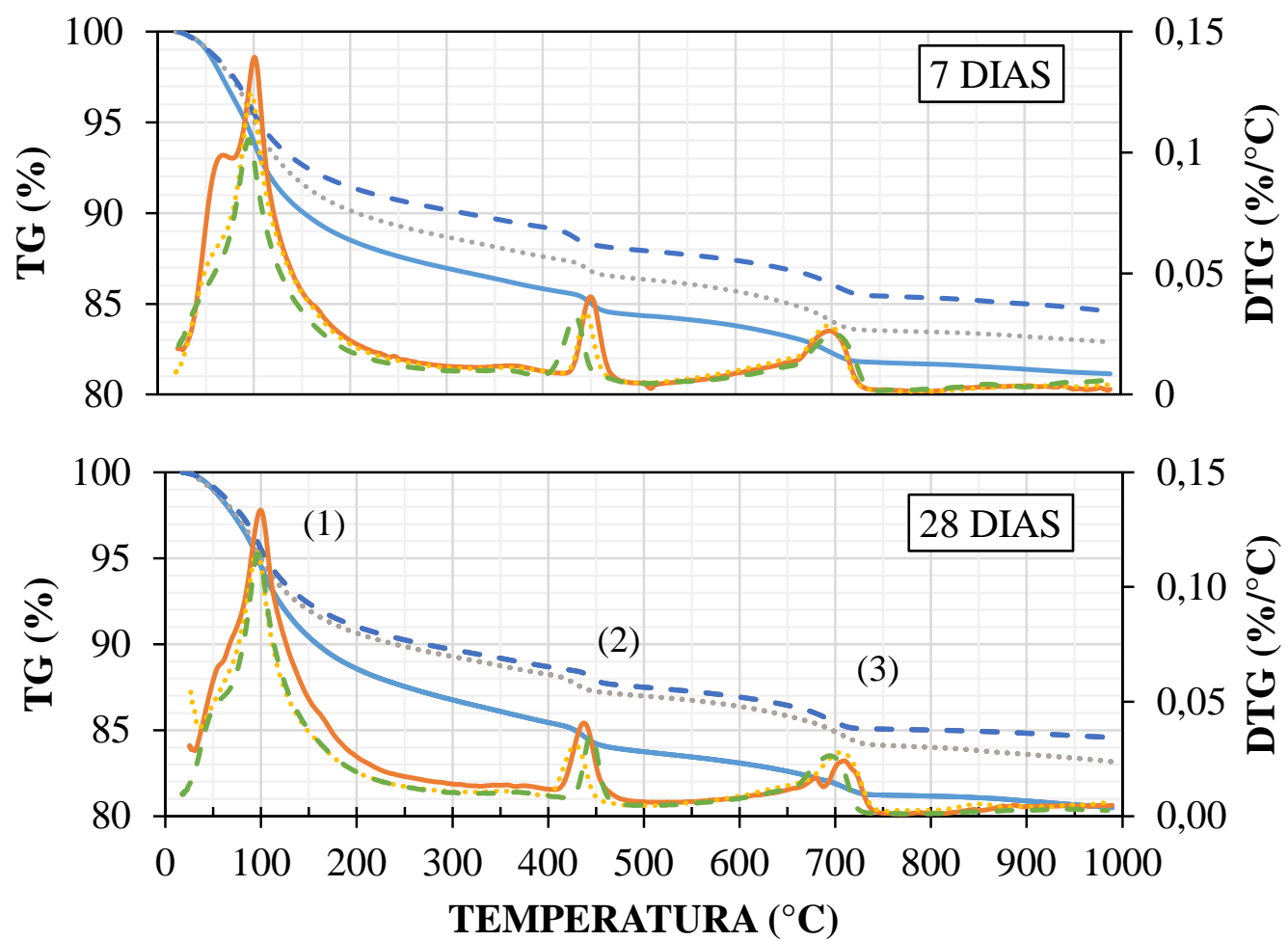

\begin{tabular}{|c|c|c|c|}
\hline — TG-P0,1 & ........ TG-P5 & - - - TG-P10 & —DTG-P0,1 \\
\hline ......... DTG-P5 & - - - DTG-P10 & $\longrightarrow$ TG-P0,1 & ........ TG-P5 \\
\hline- - - TG-P10 & — DTG-P0,1 & ….... DTG-P5 & - - - DTG-P10 \\
\hline
\end{tabular}


Figura 10 - Análise termogravimétrica das amostras
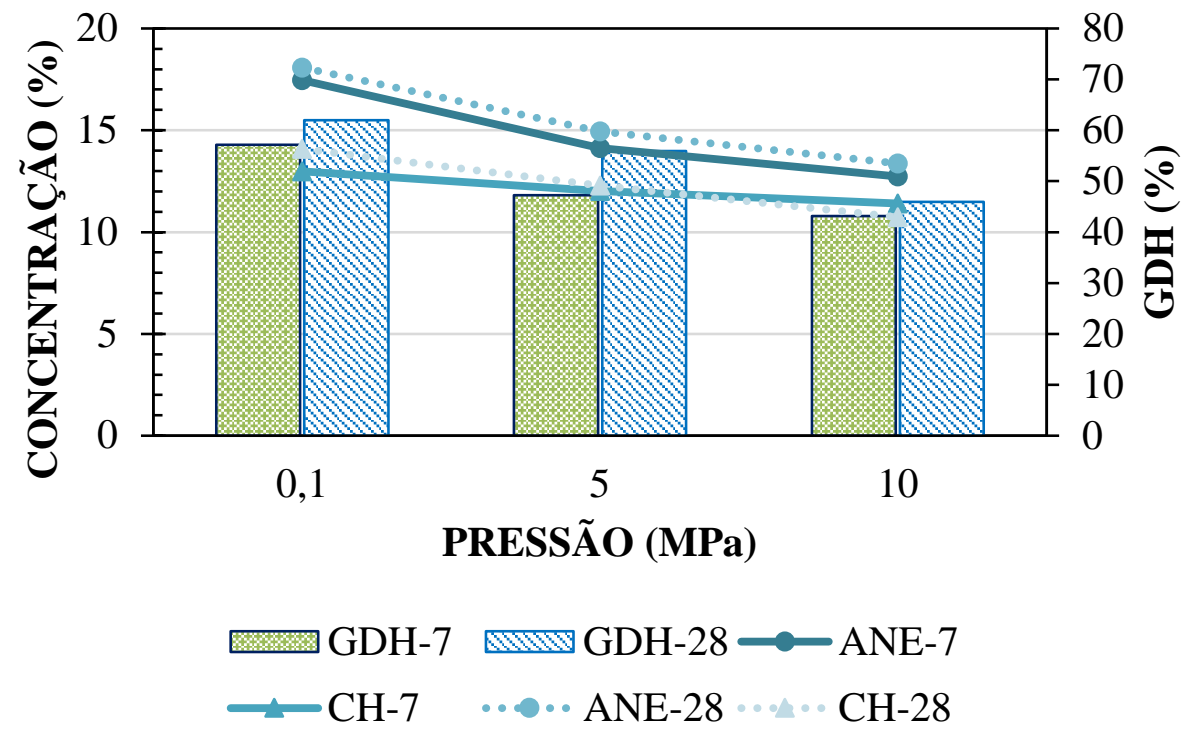

Enquanto o efeito químico da reação pozolânica baseia-se no consumo de hidróxido de cálcio para formar um C-S-H secundário e de baixa densidade, o efeito físico reflete no refinamento do tamanho dos poros e do tamanho dos grãos. No refinamento dos poros, os maiores capilares são preenchidos pelo C-S-H secundário e microporoso. No refinamento do tamanho do grão, tem-se a nucleação da portlandita na superfície do material pozolânico, substituindo os grandes e bem orientados cristais do hidróxido de cálcio por pequenos e mal orientados cristais, geralmente combinados com outros produtos de hidratação menos cristalinos (MEHTA; MONTEIRO, 2014).

Dos dados de porosidade para as mesmas amostras com 28 dias de idade foi constatado aumento da microporosidade com a pressão de compactação. Do grau de hidratação estimado por termogravimetria teve-se redução na quantidade de cimento que foi hidratado. Sendo assim, a retirada de água durante a pressurização das pastas pode ter comprometido a formação dos produtos hidratados, deixando uma maior quantidade de espaços não preenchidos pelos referidos produtos, mas sem comprometer a resistência à compressão. Também é possível que a pressão tenha favorecido a reação pozolânica, de modo que parte do hidróxido de cálcio tenha sido consumido e/ou convertido em pequenos cristais, o que, juntamente com o C-S-H secundário, contribuiu com o aumento da microporosidade das amostras.

\section{Conclusão}

Neste trabalho foi investigado o efeito da aplicação de pressão no estado fresco de pastas de cimento nas idades de 7 e 28 dias. Dos resultados apresentados, concluiu-se que:

(a) a propriedade de massa específica pode ser utilizada como indicador da eficiência de compactação, como um critério de qualidade da produção, dada a relação positiva com o nível de pressão aplicado;

(b) as propriedades de módulo de elasticidade dinâmico e resistência à compressão foram igualmente favorecidas pelo aumento da idade e da pressão de compactação;

(c) os dados de porosimetria indicam que a aplicação de pressão alterou a estrutura e a distribuição de poros de duas formas - enquanto as bolhas de ar (diâmetro superior a $100 \mu \mathrm{m}$ ) diminuíram, aumentou-se a concentração de microporos (entre $0,02 \mu \mathrm{m}$ e $0,05 \mu \mathrm{m}$ ), a diminuição das bolhas de ar foi consequência do fenômeno físico de aproximação das partículas e retirada do excesso de água, e a concentração de microporos pode estar associada à movimentação da água remanescente na pasta, que migrou para os poros cada vez menores, criando uma interconectividade entre os poros de gel;

(d) os dados de termogravimetria também comprovaram, de duas formas, o efeito da pressão na microestrutura: se, por um lado, o aumento da pressão diminuiu o grau de hidratação final, por outro, acelerou o fim das reações de hidratação; e

(e) as imagens de microscopia corroboraram os resultados de porosimetria, uma vez que foi detectada a redução dos vazios de ar aprisionado com o aumento da pressão de cura. 


\section{Referências}

AÏTCIN, P. C. Concreto de Alto Desempenho. São Paulo: Pini, 2000.

AMERICAN SOCIETY FOR TESTING AND MATERIALS. ASTM C 215: standard test method for fundamental transverse, longitudinal and torsional resonant frequencies of concrete specimens. Philadelphia, 2014.

AMERICAN SOCIETY FOR TESTING AND MATERIALS. ASTM C39/C39M: standard test method for compressive strength of cylindrical concrete specimens. Philadelphia, 2016.

ANDRADE, T. C. C. S. D. Avaliação do Tipo de Cura nas Propriedades de Concretos Pós Reativos. Curitiba, 2015. 102 f. Dissertação (Mestrado em Engenharia de Construção Civil) Escola de Engenharia, Universidade Federal do Paraná, Curitiba, 2015.

ASSOCIAÇÃO BRASILEIRA DE NORMAS TÉCNICAS. NBR 10908: aditivos para argamassa e concreto: ensaios de uniformidade. Rio de Janeiro, 1990.

\section{ASSOCIAÇÃO BRASILEIRA DE NORMAS}

TÉCNICAS. NBR 5739: concreto: ensaio de compressão de corpos-de-prova cilíndricos. Rio de Janeiro, 2007.

AZEVEDO, N. H. Incorporação de Nanobastões de Carbeto de Silício em Matrizes Cimentícias. Florianópolis, 2015. 109 f. Dissertação (Mestrado em Engenharia Civil) - Escola de Engenharia, Universidade Federal de Santa Catarina, Florianópolis, 2015.

BAJZA, A. Structure of Compacted Cement pastes. Cement and Concrete Research, v. 13, p. 239-245, 1983.

\section{BETIOLI, A. M. Influência dos Polímeros}

MHEC e EVA na Hidratação e

Comportamento Reológico de Pastas de

Cimento Portland. Florianópolis, 2007. 211 f.

Tese (Doutorado em Engenharia Civil) - Programa de Pós-Graduação em Engenharia Civil, Universidade Federal de Santa Catarina, Florianópolis, 2007.

CASTRO, R. D.; MARTINS, H. Avaliação da Adição de Cinzas do Bagaço de Cana-de-Açúcar em Argamassas Mistas. Ambiente Construído, Porto Alegre, v. 16, n. 3, p. 137-151, jul./set. 2016.

CHEN, T.; GAO, X.; REN, M. Effects of Autoclave Curing and Fly Ash on Mechanical Properties of Ultra-High Performance Concrete. Construction and Building Materials, v. 158, p. 864-872, 2018.
DE LARRARD, F.; SEDRAN, T. Optimization of Ultra-High-Performance Concrete by the Use of a Packing Model. Cement and Concrete Research, v. 24, p. 997-1009, 1994.

HELMI, M. et al. Effects of High-

Pressure/Temperature Curing on Reactive Powder Concrete Microstructure Formation. Construction and Building Materials, v. 105, p. 554-562, 2016.

IPEK, M. et al. Effect of Pre-Setting Pressure Applied to Mechanical Behaviours of Reactive Powder Concrete During Setting Phase.

Construction and Building Materials, v. 25, p. 61-68, 2011.

İPEK, M.; YILMAZ, K.; UYSAL, M. The Effect of Pre-Setting Pressure Applied Flexural Strength and Fracture Toughness of Reactive Powder Concrete During the Setting Phase. Construction and Building Materials, v. 26, p. 459-465, 2012.

JULIANI, L. M. Avaliação das Propriedades Mecânicas do Concreto de Lajes Alveolares pré-Fabricadas Utilizando Ensaios Não Destrutivos. São Carlos, 2014. 195 f. Dissertação (Mestrado em Engenharia de Estruturas) - Escola de Engenharia de São Carlos, Universidade de São Paulo, São Carlos, 2014.

JUSTS, J. et al. Microestructural Investigations of Ultra-High Performance Concrete Obtained by Pressure Application Within the First 24 Hours of hardening. Construction Science, v. 14, p. 50-57, 2013.

KRAKOWIAK, K. J. et al. Nano-ChemoMechanical Signature of Conventional Oil-Well cement SYSTEMS: effects of elevated temperature and curing time. Cement and Concrete Research, v. 67, p. 103-121, 2015.

MADANI, H.; BAGHERI, A.; PARHIZKAR, T. The Pozzolanic Reactivity of Monodispersed Nanosilica Hydrosols and Their Influence on the Hydration Characteristics of Portland Cement. Cement and Concrete Research, v. 42, p. 15631570, 2012.

MAKUL, N.; VONGPRACUBCHAI, S.;

RATTANADECHO, P. An Experimental Study of Microwave Drying Under Low Pressure to Accelerate the Curing of Portland Cement Pastes Using a Combined Unsymmetrical Double-Fed Microwave and Vacuum System. International Journal of Heat and Mass Transfer, v. 127, p. 179-192, 2018.

MEHTA, P. K.; MONTEIRO, P. J. M. Concreto: microestrutura, propriedade e materiais. 2. ed. São Paulo: Ibracon, 2014. 
NEMATZADEH, M.; NAGHIPOUR, $M$. Compressive Strength and Modulus of Elasticity of Freshly Compressed Concrete. Construction and Building Materials, v. 34, p. 476-485, 2012.

NEVILLE, A. M. Propriedades do Concreto. 5. ed. Porto Alegre: Bookman, 2016.

PRADO, D. M.; HAACH, G. Análise Experimental e Numérica de Vigas de Concreto Armado Reforçadas ao Cisalhamento Com Laminados de CFRP. Cadernos de Engenharia de Estruturas, São Carlos, v. 15, n. 65, p. 57-60, 2013.

RICHARD, P.; CHEYREZY, M. Composition of Reactive Powder Concretes. Cement and Concrete Research, v. 25, p. 1501-1511, 1995.

ROCHA, A. A. Influência da Pressão e Temperatura de Cura e da Adição de $\mathrm{NaCl}$ e KCl no Comportamento de Pastas Para Cimentação de Poços de Petróleo. Rio de Janeiro, 2015. 211 f. Tese (Doutorado em Engenharia Civil) - Escola de Engenharia, Universidade Federal do Rio de Janeiro, Rio de Janeiro, 2015.

ROY, D. M.; GOUDA, G. R.; BOBROWSKY, A. Very High Strength Cement Pastes Prepared by Hot Pressing and Other High Pressure Techniques. Cement and Concrete Research, v. 2, p. 349366, 1972.
SARTORI, A. L. Comportamento Dinâmico de Lajes Maciças de Concreto Leve Com Pérolas de EPS. São Carlos, 2015. 251 f. Tese (Doutorado em Engenharia de Estruturas) - Escola de Engenharia, Universidade de São Paulo, São Carlos, 2015.

SCRIVENER, K. L. et al. TC 238-SCM: Hydration and Microestructure of Concrete with SCMs. Materials and Structures, v. 48, p. 835862, 2015.

TAYLOR, H. F. W. Cement Chemistry. ${ }^{\text {nd }}$. ed. London: Thomas Telford, 1997.

YANKELEVSKY, D. Z. et al. High-Pressure Uniaxial Confined Compression Tests of Mortars. Construction and Building Materials, v. 165, p. 523-532, 2018.

ZHOU, Q.; BEAUDOIN, J. J. Effect of Applied Hydrostatic Stress on the Hydration of Portland Cement and C3S. Advances in Cement Research, v. 15, n. 1, p. 9-16, 2003.

ŽIVICA, V.; KRIŽMA, M. Dependence of Efficiency of Pressure Compaction on the Cement Type Used. Construction and Building Materials, v. 25, p. 3073-3077, 2011.

\section{Agradecimentos}

Os autores agradecem ao Prof. Dr. Philippe Jean Paul Gleize e à Fapesc, pela infraestrutura do Nanotec-Lab/UFSC, que permitiu a realização deste trabalho; ao Labmetro/UFSC, que contribuiu na construção do aparato utilizado; ao Laboratório Cermat/UFSC, pelas imagens de microscopia; ao Prof. Avacir, pelas medidas de porosimetria realizadas no Laboratório de Física Nuclear Aplicada da UEL; e ao CNPq e à Capes, pelo auxílio financeiro.

\section{Carolina Noda Livi}

Sociedade Educacional de Santa Catarina | Rua Salvatina Feliciana dos Santos, 525 | Florianópolis - SC - Brasil | CEP 88034-600 | Tel: (48) 3239-4705 | E-mail: carolinanlivi@gmail.com

\section{Wellington Longuini Repette}

Departamento de Engenharia Civil | Universidade Federal de Santa Catarina | Rua J oão Pio Duarte da Silva, 205 | Florianópolis - SC Brasil | CEP 88037-000 | Tel: (48) 3721-4627 | E-mail: wellington.repette@gmail.com

Revista Ambiente Construído

Associação Nacional de Tecnologia do Ambiente Construído

Av. Osvaldo Aranha, 99 - 3o andar, Centro Porto Alegre - RS - Brasil

CEP 90035-190

Telefone: +55 (51) 3308-4084

Fax: +55 (51) 3308-4054

www. seer. ufrgs. br/ ambienteconstruido

E-mail: ambienteconstruido@ufrgs.br 